University of Wollongong

Research Online

Faculty of Social Sciences - Papers (Archive) Faculty of Arts, Social Sciences \& Humanities

2015

Factors associated with the development of depression in chronic noncancer pain patients following the onset of opioid treatment for pain

Kimberley Smith

University of New South Wales

Richard P. Mattick

University of New South Wales, r.mattick@unsw.edu.au

Raimondo Bruno

University of Tasmania

Suzanne Nielsen

University of New South Wales

Milton Cohen

University of New South Wales

See next page for additional authors

Follow this and additional works at: https://ro.uow.edu.au/sspapers

Part of the Education Commons, and the Social and Behavioral Sciences Commons

Research Online is the open access institutional repository for the University of Wollongong. For further information contact the UOW Library: research-pubs@uow.edu.au 


\title{
Factors associated with the development of depression in chronic non-cancer pain patients following the onset of opioid treatment for pain
}

\begin{abstract}
Background and aims Pharmaceutical opioid prescription rates are increasing globally, however knowledge of their long-term effects on mental health, in particular depression remains limited. This study aimed to identify factors associated with the onset of depression post-opioid use that differ to factors associated with depression post-pain. Method Participants $(N=1418)$ were a national sample prescribed opioids for chronic non-cancer pain. Age at onset of depression, pain and commencement of opioid medications were collected via structured interview. Results Six in 10 (61\%) reported lifetime depression; of those, almost half developed depression after pain and after they started opioid medications (48\%). Variables associated with post-opioid depression included lower pain self-efficacy and poorer social support, younger onset of opioid use, and difficulties and concerns with opioid medications. Conclusions The findings highlight the importance of monitoring for the emergence of mood dysfunction, particularly for those starting opioids for pain at a younger age, and consideration of psychological treatments that address self-efficacy that appears to be associated with post-opioid depression.
\end{abstract}

\section{Keywords}

treatment, development, depression, factors, chronic, associated, non-cancer, pain, patients, following, onset, opioid

\section{Disciplines}

Education | Social and Behavioral Sciences

\section{Publication Details}

Smith, K., Mattick, R. P., Bruno, R., Nielsen, S., Cohen, M., Campbell, G., Larance, B., Farrell, M. \& Degenhardt, L. (2015). Factors associated with the development of depression in chronic non-cancer pain patients following the onset of opioid treatment for pain. Journal of Affective Disorders, 184 72-80.

\section{Authors}

Kimberley Smith, Richard P. Mattick, Raimondo Bruno, Suzanne Nielsen, Milton Cohen, Gabrielle Campbell, Briony K. Larance, Michael P. Farrell, and Louisa Degenhardt 
Factors associated with the development of depression in chronic non-cancer pain patients following the onset of opioid treatment for pain

Kimberley Smith ${ }^{1}$, Richard P. Mattick ${ }^{1}$, Raimondo Bruno ${ }^{2}$, Suzanne Nielsen ${ }^{1}$, Milton Cohen $^{4}$, Gabrielle CampbelI ${ }^{1}$, Briony Larance ${ }^{1}$, Michael Farrell ${ }^{1}$ and Louisa Degenhardt ${ }^{1,5-7}$

1) National Drug and Alcohol Research Centre, UNSW, Australia

2) School of Medicine, University of Tasmania, Australia

3) South East Sydney Local Health District (SESLHD) Drug and Alcohol Services, Australia

4) St Vincent's Clinical School, UNSW Medicine, UNSW Australia

5) School of Population and Global Health, University of Melbourne, Australia

6) Murdoch Children's Research Institute, Australia

7) Department of Global Health, School of Public Health, University of Washington, USA

\section{Corresponding Author:}

Gabrielle Campbell

NDARC, University of New South Wales, Sydney NSW 2052, Australia.

Tel: +61 (02) 93850286

Fax: +61293850222

E-mail: g.campbell@unsw.edu.au

Word count: 4166 


\begin{abstract}
Background and aims: Pharmaceutical opioid prescription rates are increasing globally, however knowledge of their long-term effects on mental health, in particular depression remains limited. This study aimed to identify factors associated with the onset of depression post-opioid use that differ to factors associated with depression post-pain.
\end{abstract}

Method: Participants $(\mathrm{N}=1,418)$ were a national sample prescribed opioids for chronic noncancer pain. Age at onset of depression, pain and commencement of opioid medications were collected via structured interview.

Results: Six in ten (61\%) reported lifetime depression; of those, almost half developed depression after pain and after they started opioid medications (48\%). Variables associated with post-opioid depression included lower pain self-efficacy and poorer social support, younger onset of opioid use, and difficulties and concerns with opioid medications.

Conclusions: The findings highlight the importance of monitoring for the emergence of mood dysfunction, particularly for those starting opioids for pain at a younger age, and consideration of psychological treatments that address self-efficacy that appears to be associated with post-opioid depression.

Keywords: depression, chronic pain, pharmaceutical opioids, self-efficacy 


\section{Introduction}

The global prevalence of chronic non-cancer pain (CNCP) is estimated at one adult in five, (1) with the 2010 Global Burden of Disease Study reporting chronic low back pain as the largest cause of years lost to disability (2).

Pharmaceutical opioids are increasingly used for treatment of CNCP. (3). Despite the link between CNCP and poorer mental health being well established in the literature $(4,5)$, little is known about the impact thatcommencement of prescribed opioids may have on this relationship (i.e., is use of opioids associated with an increased or decreased likelihood of depression).

A growing body of research has focused on "adverse selection" (6) whereby individuals with pre-existing mental illness are more likely to be prescribed pharmaceutical opioids for CNCP and at higher doses (7). A recent cohort study found individuals who were receiving opioid treatment were more likely to report high levels of psychological distress compared with individuals not receiving opioid medications (8). Additionally, opioid-naïve patients with chronic pain without a recent history of depression have been found to be at greater risk of developing depression the longer they were taking opioid medications (9).

With an ageing population in Western countries and increasing opioid prescribing in many of these, it is timely to assess the possible association between pharmaceutical opioids and risk of developing depression. The current study examines data from a large community sample, including in-depth measures of mental health, and self-reported opioid consumption (rather than prescribing data), while controlling for severity of pain and preexisting depression.

The aims of the study were:

(a) to estimate the prevalence of depression that occurs after the onset of pain and also after the initiation of prescribed opioid treatment for pain;

(b) to determine demographic and clinical characteristics and factors associated with those who develop depression post-pain; and

(c) to determine demographic and clinical characteristics and factors associated with those who develop depression post-opioid treatment. 


\section{Methods}

\section{Study Design}

This study draws on baseline data collected for the Pain and Opioids IN Treatment (POINT) study, a national cohort of 1,514 individuals taking pharmaceutical opioids for chronic noncancer pain. Recruitment of this cohort has been described elsewhere (10). In brief, community pharmacists referred patients prescribed strong opioids to complete a telephone interview and self-complete survey at baseline and then three further time points.

The study was approved by the Human Research Ethics Committee of the University of New South Wales, Australia (HREC reference: \#HC12149). It also received A1 Australian National Pharmacy Guild Approval to approach pharmacists to assist with recruitment (Approval \#815).

\section{Eligibility Criteria}

POINT participants were screened and considered eligible if they were 18 years or older; competent in English; mentally and physically able to complete telephone and self-complete interviews; living with chronic non-cancer pain for at least 3 months; prescribed a restricted opioid (such as morphine, oxycodone, fentanyl or codeine as a single ingredient which are classified under schedule 8 in the Australian Uniform Scheduling of Medicines and Poisons, Poisons Standard 2012 (11)); meaning they are controlled drugs subject to restrictions to reduce abuse, misuse and dependence) and having taken such opioids for CNCP for more than 6 weeks. A history of injecting drug use (IDU) did not exclude participation, however those currently prescribed pharmaceutical opioids solely as opioid substitution therapy (OST) for heroin dependence, or those being treated with opioids for cancer pain, were not eligible.

\section{Participants}

For the purpose of the current study, only participants who contributed data on the age at onset of depression, age at onset of pain and age at commencing pharmaceutical opioids were included in the analyses $(n=1,418)$. Those who reported lifetime depression $(n=860)$ 
for descriptive purposes could be divided into three groups; those who developed depression prior to pain ( $n=236$ ); those who developed depression after the onset of pain but prior to commencing opioids ( $n=205$ excluding missing data); and those who developed depression after pain and after they started opioid medications ( $n=416)$.

To compare the temporal relationships between onset of pain and onset of depression, participants who reported whether or not they had experienced lifetime depression $(n=1,379)$ were divided into three groups: the 'no depression' group included those who reported no lifetime history of depression $(n=519)$; those whose age at onset of depression preceded their age at onset of pain reported were assigned to the 'pre-pain depression' group ( $n=236)$; and those whose age at onset of pain preceded their age at onset of depression were assigned to the 'post-pain depression' group $(n=624)$. Due to missing data on the essential age at onset variables, 39 cases were not included.

To compare the temporal relationships between onset of opioid treatment and onset of depression, $n=1,361$ participants were allocated to three groups according to whether the onset of depression occurred before or after the initiation of opioid treatment. As above, the 'no depression' group reported no lifetime history of depression ( $n=519)$; those who reported that depression preceded commencement of opioid medications were assigned to the 'pre-opioid depression' group ( $n=426)$; and those whose commencement of opioids preceded depression were assigned to the 'post-opioid depression' group $(n=416)$. Due to missing data on the essential age at onset variables 57 cases were not included.

\section{Measures}

The measures, tools, and domains collected were based on recommendations made under the auspices of the Initiative on Methods, Measurement, and Pain Assessment in Clinical Trials (IMMPACT) $(12,13)$. Full details of the measures used in the study have been documented elsewhere (10), and are described briefly below.

\section{Pain and physical health related measures}

Data were collected on participants' pain history. The Brief Pain Inventory (14) was utilised to assess current pain severity and interference from pain on a rating scale from 0 to 10 , with higher scores indicative of higher pain severity and interference. Pain-related self- 
efficacy beliefs were assessed using the Pain Self-Efficacy Questionnaire (PSEQ) (15) which generates a total score from 0-60. Higher scores on the scale reflect greater confidence in the participant's ability to perform a range of activities including household chores, socialising, work and to cope with pain. The Washington Group Scale (16) was used to measure physical functioning providing a total score between $0-18$, with higher scores indicating greater degrees of disability.

\section{Mental health and substance use}

Participants were asked if they had ever been diagnosed with any mental health condition, including depression, anxiety, post-traumatic stress disorder, and borderline personality disorder. Current depression and anxiety were assessed through scores on the PHQ-9 (17) and GAD-7 (18) from the Patient Health Questionnaire (19). Continuous scores on the Social Interaction Anxiety Scale (SIAS-6) (20) and Social Phobia Scale (SPS-6) (20) were used to derive current symptoms of social anxiety and phobia. Current agoraphobia and panic disorder were screened using the Mini International Neuropsychiatric Interview (MINI) (21), each coded as binary variables. Using the National Survey of Mental Health and Wellbeing (22) version of the Composite International Diagnostic Interview (CIDI) participants were screened for possible diagnoses of borderline personality disorder in accordance with International Classification of Diseases-10 (ICD-10) criteria. Post-traumatic stress disorder (PTSD) was measured using the Primary Care PTSD screen (PC-PTSD) with three or more symptoms in the past month indicative of current PTSD (23).

Participants were asked about lifetime and past 12 month alcohol and illicit drug use apart from pharmaceutical opioids, as difficulties with opioids were measured using PODS. Lifetime drug and alcohol use disorders were assessed via the CIDI (24) alcohol and illicit drug use module in accordance with ICD-10 criteria. Any lifetime substance use disorder included both harmful use and dependence with current symptoms defined as more than 3 experienced in the past 12 months.

\section{Opioid medications}

Participants were asked about opioid medication history. Daily oral morphine equivalent (OME) doses (mg) were calculated using published conversion rates that were synthesised from international literature (25). OME was calculated for each participant from the 7-day 
medication diary which took into account all type of opioids, including over-the-counter, that the participant self-reported they had taken in the preceding week. A weekly mean was calculated, taking to account any changes in OME over the week, and OME daily dose was derived from that.

To assess participants' current concerns and problems in regards to the use of prescription opioids the Prescribed Opioids Difficulty Scale (PODS) (26) was included. The 15-item scale generates a continuous score out of 60 ; a cut-off of $\geq 8$ indicates at least intermediate levels of participant concern or difficulties (26).

\section{Data Analysis}

All analyses were conducted using IBM SPSS statistics v22 (SPSS, INC., Chicago. IL, USA). The groups established on the basis of onset of depression were compared with respect to demographic factors, current pain and pain history, opioid medications and current and lifetime mental health and substance use. Analyses applied logistic regression models with odds-ratios and $95 \%$ confidence intervals for categorical variables; means and t-tests for normally distributed continuous variables; and medians, inter-quartile range, and MannWhitney $\mathrm{U}$ for non-normal continuous variables.

Univariate and multivariate multinomial regression models were conducted to examine factors associated with a) depression following the onset of pain; and b) depression following the onset of treatment with opioids. Relative Risk ratios (RRR) and $95 \% \mathrm{Cl}$ are reported. In this series of analyses, for consistency between univariate and multivariate models, only participants who had completed the baseline interview, survey and medication diary were included. All variables were entered into multivariate models and were controlled for in addition to mental health problems:, PTSD, agoraphobia, panic and borderline personality. When examining factors associated with developing depression after the onset of pain, complete data from $n=809$ participants were included. A multivariate logistic regression was also performed to examine any characteristic differences between those who developed depression after pain but before opioids $(n=205)$ and those who developed depression after pain and after opioids ( $n=416)$. 


\section{Results}

\section{Demographic, pain and medication characteristics}

Of the 1418 participants in this analysis, 44\% were male with a median age of 58 years $(I Q R=48-68)$. The average pain duration was 10 years $(I Q R=4.5-20)$ with current pain severity rated at a mean of $5.1(\mathrm{SD}=1.8)$, and mean pain interference of 5.7 ( $S D=2.3)$ Participants reported taking pharmaceutical opioids continuously for a median of 4 years (IQR=1.5-10) with the average daily oral morphine equivalent dose being 70mg (IQR=35mg-142mg). Sixtyone percent of participants reported a lifetime incidence of depression.

When comparing the 39 missing cases not included in the analyses according to onset of depression post-pain, there were no significant differences in gender, age, pain duration, pain severity or OME dose. However, those omitted from the analyses reported a longer duration of opioid use ( $M d n=10, I Q R=4-13)$. There were no significant differences between the 57 missing cases and those included in the analyses according to onset of depression post-opioids in gender, age, pain duration, opioid treatment duration or OME dose. However, those excluded from the analyses reported a greater pain severity $(M=5.8$, $\mathrm{SD}=1.7)$.

\section{Group comparisons according to onset of depression post-pain.}

. Overall, measures of pain and medication use distinguished participants with a lifetime history of depression from their counterparts without depression, regardless of time of onset. Compared with the 'pre-pain depression' group, the 'post-pain depression' group was more likely to be male and have a lower income (Table 1). Compared with both the 'nodepression' group and 'pre-pain depression' group, the 'post-pain depression' group was more likely to have changed employment status due to pain, tended to have been experiencing pain for longer, reported greater pain interference, poorer physical functioning as observed through higher scores on the Washington Group Scale and reported a higher number of medication side effects. They had started taking pharmaceutical opioids at a younger age and had used them for longer. Compared with the 'no-depression' group, the 'post-pain depression' group was younger, less likely to be in a relationship, reported greater pain severity and less confidence in ability to cope with pain (as measured with the 
PSEQ). The 'post-pain depression' group reported a higher OME dose and was more likely to have problems or concerns about their opioid medications than the 'no-depression' group. The 'post-pain depression' group was more likely to report lower social support, any of the mental health conditions examined, or a lifetime history of substance use disorders compared with those reporting no depression.

\section{INSERT TABLE 1.}

\section{Associations with developing depression post-pain.}

From the multivariate analysis, factors associated with developing depression before onset of pain, compared with those who had never developed depression were; a younger age, female, not being in a current relationship, a lower pain self-efficacy score, older at onset of pain, reported more problems associated with their opioid medication but reported fewer side effects from medication. Factors associated with developing depression post-pain (compared with those who never developed depression) were being female, a change in employment status due to pain, poorer pain self-efficacy, poorer physical functioning, a younger age of onset of pain and lower levels of social support (Table 2).

\section{INSERT TABLE 2.}

\section{Group comparisons according to onset of depression post-opioids.}

The 'post-opioid depression' group was more likely to be male than the 'pre-opioid depression' group (Table 3). Compared with the 'no depression' group, the 'post-opioid depression' group was less likely to be in a relationship, reported greater pain severity and interference, less confidence in coping with pain (as measured with the PSEQ), reported poorer physical functioning and was more likely to report all mental health conditions and/or a lifetime substance use disorder. Compared with both the 'no-depression' group and 'pre-opioid depression' group, the 'post-opioid depression' group was significantly younger, and more likely to have changed employment status due to pain. The 'post-opioid depression' group reported higher OME doses, had started pharmaceutical opioids at a younger age and had taken them for longer. They were more likely to have an intermediate to high score on the PODS (indicating greater difficulties with their pharmaceutical opioids) than the other two groups, reported a higher number of medication side effects and had 
higher scores on measures of current social anxiety and social phobia than either of the other groups.

\section{INSERT TABLE 3.}

\section{Associations with developing depression post-opioids}

From the multivariate analysis, participants that developed depression pre-opioids, compared with those that never developed depression were, younger, female, less likely to be in a relationship, lower pain and self-efficacy score, poorer physical health, younger at age of pain onset and older at opioid medication initiation. Participants who developed depression following opioid use were identified as having started pharmaceutical opioids at a younger age, poorer physical health, more likely to report difficulties with their opioid medications and having less social support. (Table 4).

Comparison of those who developed depression post-pain, pre-opioid with those who developed depression post-pain, post opioid

A multivariate analysis was conducted to compare those who developed depression after the onset of pain but before commencement of opioid $(n=205)$ with those who developed depression after commencement of opioids $(n=416)$, using the same variables as listed in Tables 2 and 4 (not shown). Developing depression post-opioids was associated with increased odds of being older $1.05(95 \% \mathrm{Cl}, 1.01-1.08)$, being male (OR=1.75; $95 \% \mathrm{Cl}, 1.00$ $3.07)$, being older at age of pain onset $(A O R=1.09 ; 95 \% \mathrm{Cl}, 1.06-1.11)$ and being younger at commencement of pharmaceutical opioids $(A O R=0.88 ; 95 \% \mathrm{Cl}, 0.85-0.91)$. All other variables did not significantly differ.

INSERT TABLE 4. 


\section{Discussion}

Although the association between chronic pain and depression has been documented $(4,5)$, less work has examined the potential impact of pharmaceutical opioid therapy on the timing of development of depression. The current study aimed to identify factors associated with depression developing after the commencement of opioid medications that might differ from those associated with the onset of pain itself. Where previous research has been limited by measuring opioid use through prescriptions or specific populations $(8,9)$, the current study is unique in using a community sample self-reporting consumption of opioids, including those purchased over the counter, and additionally controlling for pain-related factors.

\section{Prevalence and characteristics of depression in a chronic pain sample}

Consistent with other literature in the area (5) the prevalence of depression in this cohort was high, with more than $60 \%$ of the sample experiencing depression at some point in their lifetime, $66 \%$ of those reporting symptoms in the past 12 months, and $46 \%$ reporting symptoms of moderate to severe depression in the past two weeks. Of those $60 \%(n=860)$ who reported lifetime depression, around a quarter developed depression prior to pain ( $n=236$ ), a quarter ( $n=205$ excluding missing data) developed depression after the onset of pain but prior to commencing opioids, whilst almost half developed depression after pain and after they started opioid medications $(n=416)$. Compared with those with no history of depression, those who reported depression also reported a greater number of medication side effects, greater pain severity and interference, more opioid medication-related problems, and were more likely to report current mental health and substance use problems, irrespective of whether their depression developed following the onset of pain or of commencing opioids for pain. Thus, these results indicate a complex group experiencing a multitude of difficulties and possibly requiring a multidisciplinary healthcare approach to address their needs.

Furthermore, all depression groups reported taking a higher daily oral morphine equivalent dose than the non-depressed groups, lending support to the concept from research of adverse selection $(6,7)$, and raising the important questions of how best to concurrently treat pain and mental health and how to manage risk of adverse effects associated with 
higher doses of opioids in this group. Long-term follow up studies of patients naïve to opioid medications would be better able to address this issue.

\section{Factors associated with developing depression after the onset of pain}

Factors associated with developing depression post-onset of pain, after controlling for all other variables in the multivariate analyses, included having poorer physical functioning, lower levels of pain self-efficacy, being younger at the onset of pain and having lower social support. This highlights the need to pay particular attention to the mental health of those presenting with pain at a young age. Social support and appreciation of self-efficacy in relation to pain may be modifiable factors that could respond to psychological therapies such as CBT, self-help or support groups $(27,28)$. Multimodal pain treatments (including psychological therapies) have been shown to be effective in treating chronic pain $(29,30)$.

The context of this sample coming from a pain cohort must also be kept in mind. The bidirectional relationship between pain and depression may affect treatment options considered by physicians, noting findings that depression may change the experience of pain. "Major therapeutic implications arise out of this relationship (12, 31)."

\section{Factors associated with developing depression after commencing opioid medications}

In the current study, those who no history of depression prior to starting opioid medications, who went on to develop depression were more likely to have commenced opioid medication at a younger age, to have experienced greater difficulties with their opioid medications and to have less social support. Those who developed depression after opioids (and after pain) differed from those who developed depression prior to commencing opioids (but after pain) tending to be older, more likely to be male, were older at age of pain onset and younger at age of starting opioid medications. Whereas previous findings $(7,9)$ suggested that dose and duration of opioid medication were related to depression, these variables were not found to be significant once controlling for important factors such as duration of pain and concurrent mental health conditions.

There are a number of possible explanations for the relationship between opioid treatment for pain and development of depression. Scherrer et al. (2013) applied neural research on addiction (32) to suggest that opioids may increase the threshold of the 'reward pathway' so 
that previous instigators of pleasure are no longer able to induce the same effect. Alternatively, there is the possibility that sedative effects of opioid medications may induce symptoms associated with depression (33). A further possibility is 'substance-induced depressive disorder' as stated in DSM 5 (34). This would be particularly problematic in those who may be using medications, alcohol or other substances as a method of coping, emphasising the need for non-medication therapies for pain to be thoroughly explored. Most likely, a number of psychosocial factors are involved with the development of depression. For instance poorer coping, multiple health conditions and chronic illness have been shown to affect mood (35) in addition to lower social support and change in lifestyle, such as being unable to work.

Interestingly, those who developed depression prior to the commencement of opioids tended to commence opioids at an older age compared with the no depression group. This is in contrast to those who developed depression post-opioids who tended to commence opioids at a younger age than the no depression group. Similarly, those who developed depression prior to the onset of pain tended to be older at the onset of pain compared to the no depression group, whereas those who developed depression post-pain tended to be younger at the onset of pain. This may indicate that physicians were reluctant to prescribe opioid medications to people already experiencing depression, contrary to previous research on adverse selection $(6,7)$. Alternatively, it may be that people experiencing depression delayed seeking help for their chronic pain and consequently, delayed treatment.

The relationship between starting pharmaceutical opioids at a younger age and developing depression may reflect other stressors, such as dealing with high levels of pain, side effects from opioid medications and disability (when being younger is usually associated with being in good health), as seen through the increased likelihood of changed employment status. However neither current physical functioning nor pain severity was observed to be significantly related to post-opioid depression, and interestingly the relationship remained significant when controlling for age at pain onset. An alternate explanation may consider the role of the prescriber, whereby the physician is responding to a high level of distress, particularly in a younger patient, by prescribing opioid medications for "pain" rather than exploring other factors that may be contributing. This raises the issue of whether prescribing 
opioids in such circumstances is appropriate and reinforces the need for a thorough assessment of psychosocial background prior to initiating opioid treatments.

The more complex profile of health needs in the younger participants of this chronic pain sample has been examined in more detail elsewhere (36). However, in light of an increased likelihood of younger participants reporting problems and concerns about their opioids (PODS), it is possible that this group may be trying to self-manage depression or other distress through their opioid medications or other substances: this has been termed 'chemical coping' (37). Although not possible to confirm with our study design, future work may be able to explore this hypothesis.

\section{Limitations and implications}

Due to the design of the study, data on onset of depression, pain and opioid commencement were collected retrospectively and hence are dependent on participant recall. Future research may investigate this temporal relationship prospectively, through following patients who are naïve to opioid medications and by undertaking regular assessments of emotional wellbeing, including the impact of effective treatments for mood disorders on pain outcomes. Further, there is the possibility that participants' self-report of depression may not be concordant with a clinical diagnosis of depression. Due to the nature of the POINT study, this concordance could not be measured. It is important to note that this study has addressed characteristics of the participant taking prescription opioids but the role of the prescribers of such medicines was not explored (38).

Although it is not possible to interpret the relationship between depression and opioid medications in terms of causality, specifically, whether difficulties and concerns surrounding opioid use may contribute to depression or vice versa, the findings still have important implications. All depression groups were experiencing a wide range of difficulties, highlighting the need to screen for, and appropriately respond to, risk-factors in opioid prescribing (39) and closely monitor for evidence of beneficial effect from opioids and emergence of problematic behaviours (40). Furthermore, in accordance with clinical guidelines, it is important for physicians to recognise the importance of screening for depression prior to initiating treatment for pain and to monitor for the emergence of mood dysfunction during the course of treatment, especially in individuals with the risk 
characteristics that have been raised here. Psychological interventions may be of benefit for depression symptoms given evidence of their effectiveness in both depression and pain, and additionally provide a possible intervention without increasing medication use, and hence risk of sedative effects (41).

\section{Conclusions}

Although there are similarities between those who develop depression following the onset of pain and those who develop depression after initiating opioid treatment for pain, the latter group, especially those commencing opioids at a younger age appear to be a greater risk of poorer outcome of treatment for pain and of developing difficulties with their opioid medications. These results reflect the complex comorbidities of chronic pain, especially depression and underscore the necessity for multidimensional assessment. 


\section{Acknowledgements}

The authors would like to acknowledge and thank the POINT participants for giving their time and sharing their experiences.

Thanks to Chief Investigators Wayne Hall, Nicholas Lintzeris and Fiona Shand who assisted with development of the overall study design. Thanks to Jessica Belcher, Sarah Freckleton, Bianca Hoban, Anika Martin, Ranira Moodley, and Rachel Urquhart-Secord at NDARC, for their contribution to data collection.

Thanks to the Pharmacy Guild of Australia, the NSW Pharmacy Guild, and Pain Australia, for their support and assistance during the study and dissemination. Thanks also to the POINT advisory committee for their advice on the design and conduct of the study.

\section{Author Contributions}

KS led writing for the first draft and analysis with guidance from RPM, RB, SN and LD. All authors contributed to the critical review of the manuscript. RPM, RB, SN, MC, GC, BL and LD contributed to the development of the parent study for the purposes of the funding proposal and/or development of the study design. All authors approved the final version of the manuscript.

\section{Funding}

This study received funding from the Australian National Health and Medical Research Council (NHMRC, \#1022522). RPM, SN, BL and LD are supported by NHMRC research fellowships (\#1041472, \#1073858, \#1013803, \#569738 and \#1045318). The National Drug and Alcohol Research Centre at the University of NSW is supported by funding from the Australian Government under the Substance Misuse Prevention and Service Improvements Grant Fund. The funder had no role in the design, conduct, analysis, interpretation or writeup of this manuscript.

\section{Conflict of interest}

\section{Declarations of interest}

RPM, RB, SN, GC, BL, and LD have all been investigators on untied investigator-driven educational grants funded by Reckitt Benckiser for post-marketing surveillance studies of 
buprenorphine-naloxone tablets and film, development of an opioid-related behaviour scale, and/or a study examining the uptake of opioid substitution therapy among chronic non-cancer pain patients. $\mathrm{RB}, \mathrm{BL}$ and $\mathrm{LD}$ have received an untied educational grant from Mundipharma for post-marketing surveillance studies of Reformulated OxyContin ${ }^{\circledR}$. MC has received payments from Mundipharma Pty Limited for preparation and presentation of educational material. 


\section{References}

1. Vos $T$, Flaxman $A D$, Naghavi $M$, Lozano R, Michaud C, Ezzati $M$, et al. Years lived with disability (YLDs) for 1160 sequelae of 289 diseases and injuries 1990-2010: a systematic analysis for the Global Burden of Disease Study 2010. Lancet. 2012 Dec 15;380(9859):2163-96. PubMed PMID: 23245607. Epub 2012/12/19. eng.

2. Hoy D, March L, Brooks P, Blyth F, Woolf A, Bain C, et al. The global burden of low back pain: estimates from the Global Burden of Disease 2010 study. Annals of the Rheumatic Diseases. 2014 June 1, 2014;73(6):968-74.

3. Leong M, Murnion B, Haber PS. Examination of opioid prescribing in Australia from 1992 to 2007. Internal Medicine Journal. 2009;39(10):676-81.

4. Fishbain DA, Cutler R, Rosomoff HL, Rosomoff RS. Chronic Pain-Associated Depression: Antecedent or Consequence of Chronic Pain? A Review. The Clinical Journal of Pain. 1997;13(2):11637.

5. Kroenke K, Wu J, Bair MJ, Krebs EE, Damush TM, Tu W. Reciprocal Relationship Between Pain and Depression: A 12-Month Longitudinal Analysis in Primary Care. The Journal of Pain. 2011 9//;12(9):964-73.

6. Howe $C Q$, Sullivan MD. The missing ' $P$ ' in pain management: how the current opioid epidemic highlights the need for psychiatric services in chronic pain care. Gen Hosp Psychiatry. 2014 Jan-Feb;36(1):99-104. PubMed PMID: 24211157.

7. Braden JB, Sullivan MD, Ray GT, Saunders K, Merrill J, Silverberg MJ, et al. Trends in longterm opioid therapy for noncancer pain among persons with a history of depression. Gen Hosp Psychiatry. 2009 Nov-Dec;31(6):564-70. PubMed PMID: 19892215. Pubmed Central PMCID: 2774904.

8. Rogers KD, Kemp A, McLachlan AJ, Blyth F. Adverse Selection? A Multi-Dimensional Profile of People Dispensed Opioid Analgesics for Persistent Non-Cancer Pain. PLoS One. 2013;8(12):e80095.

9. Scherrer JF, Svrakic DM, Freedland KE, Chrusciel T, Balasubramanian S, Bucholz KK, et al. Prescription opioid analgesics increase the risk of depression. J Gen Intern Med. 2014 Mar;29(3):4919. PubMed PMID: 24165926. Pubmed Central PMCID: 3930792.

10. Campbell G, Mattick R, Bruno R, Larance B, Nielsen S, Cohen M, et al. Cohort protocol paper: the Pain and Opioids In Treatment (POINT) study. BMC pharmacology \& toxicology. 2014;15(1):17. PubMed PMID: 24646721. Pubmed Central PMCID: 4000138.

11. Sullivan MD. The quest for rational chronic pain pharmacotherapy. General Hospital Psychiatry. 2009 May 2009/June;31 (3):203-5. PubMed PMID: 2009202893. English.

12. Dworkin RH, Turk DC, Farrar JT, Haythornthwaite JA, Jensen MP, Katz NP, et al. Core outcome measures for chronic pain clinical trials: IMMPACT recommendations. Pain. 2005;113(12):9-19.

13. Turk DC, Dworkin RH, Allen RR, Bellamy N, Brandenburg N, Carr DB, et al. Core outcome domains for chronic pain clinical trials: IMMPACT recommendations. Pain. 2003 Dec;106(3):337-45. PubMed PMID: 14659516. Epub 2003/12/09. eng.

14. Cleeland C, Ryan K. Pain assessment: global use of the Brief Pain Inventory. Ann Acad Med Singapore. 1994;23(2):129.

15. Nicholas MK. The pain self-efficacy questionnaire: Taking pain into account. European Journal of Pain. 2007;11(2):153-63.

16. Centre for Disease Control and Prevention. Overview of Implementation Protocols for Testing the Washington Group Short Set of Questions on Disability. Washington DC: Centre for Disease Control and Prevention, 2006.

17. Kroenke K, Spitzer R, Williams JBW. The PHQ-9: Validity of a Brief Depression Severity Measure. Journal of General Internal Medicine. 2001;16(9):606-13. 
18. Spitzer RL, Kroenke K, Williams JBW, Lowe B. A brief measure for assessing generalized anxiety disorder: the GAD-7. Archives of Internal Medicine. 2006 May 22;166(10):1092-7. PubMed PMID: 16717171. English.

19. Kroenke K, Spitzer RL, Williams JBW, Lowe B. The Patient Health Questionnaire Somatic, Anxiety, and Depressive Symptom Scales: a systematic review. Gen Hosp Psychiatry. 2010 JulAug;32(4):345-59. PubMed PMID: 20633738. English.

20. Mattick RP, Clarke JC. Development and validation of measures of social phobia scrutiny fear and social interaction anxiety. Behav Res Ther. 1998 Apr;36(4):455-70. PubMed PMID: 9670605. Epub 1998/07/22. eng.

21. Sheehan DV, Lecrubier $\mathrm{Y}$, Sheehan KH, Amorim P, Janavs J, Weiller E, et al. The MiniInternational Neuropsychiatric Interview (M.I.N.I.): the development and validation of a structured diagnostic psychiatric interview for DSM-IV and ICD-10. J Clin Psychiatry. 1998;59 Suppl 20:2233;quiz 4-57. PubMed PMID: 9881538. Epub 1999/01/09. eng.

22. Andrews G, Hall, W., Teeson, M \& Henderson, S. The Mental Health of Australians: National Survey of Mental Health and Wellbeing. Care CDoHaA; 1999.

23. Prins A, Ouimette P, Kimerling R, Camerond RP, Hugelshofer DS, Shaw-Hegwer J, et al. The primary care PTSD screen (PC-PTSD): development and operating characteristics. International Journal of Psychiatry in Clinical Practice. 2004;9(1):9-14.

24. World Health Organization. Composite International Diagnostic Interview, Version 3.0. Geneva: World Health Organization; 2001.

25. Nielsen S, Degenhardt L, Hoban B, Gisev N. Comparing opioids: A guide to estimating oral morphine equivalents (OME) in research. NDARC Technical Report No. 329. National Drug and Alcohol Research Centre, UNSW Australia, 2014 Contract No.: Technical Report No. 329.

26. Sullivan M, Von Korff M, Banta-Green C, Merrill J, Saunders K. Problems and concerns of patients receiving chronic opioid therapy for chronic non-cancer pain. (19 refs.): University of Washington, School of Medicine, Department of Psychiatry \& Behavioral Science, Box 356560, Seattle, WA 98195. [E-mail: sullimar@u.washington.edu]; 2010.

27. Hughes S, Jaremka LM, Alfano CM, Glaser R, Povoski SP, Lipari AM, et al. Social support predicts inflammation, pain, and depressive symptoms: longitudinal relationships among breast cancer survivors. Psychoneuroendocrinology. 2014 Apr;42:38-44. PubMed PMID: 24636499. Pubmed Central PMCID: PMC3970938. Epub 2014/03/19. eng.

28. Eccleston C, Fisher E, Craig L, Duggan GB, Rosser BA, Keogh E. Psychological therapies (Internet-delivered) for the management of chronic pain in adults. Cochrane Database Syst Rev. 2014;2:CD010152. PubMed PMID: 24574082. Epub 2014/02/28. eng.

29. Flor H, Fydrich T, Turk DC. Efficacy of multidisciplinary pain treatment centers: a metaanalytic review. Pain. 1992 May;49(2):221-30. PubMed PMID: 1535122. Epub 1992/05/01. eng.

30. Karjalainen $K$, Malmivaara A, van Tulder $M$, Roine $R$, Jauhiainen $M$, Hurri $H$, et al. Multidisciplinary biopsychosocial rehabilitation for neck and shoulder pain among working age adults. The Cochrane database of systematic reviews. 2003 (2):CD002194. PubMed PMID: 12804428. Epub 2003/06/14. eng.

31. McQuay HJ, Tramer M, Nye BA, Carroll D, Wiffen PJ, Moore RA. A systematic review of antidepressants in neuropathic pain. Pain. 1996 Dec;68(2-3):217-27. PubMed PMID: 9121808. Epub 1996/12/01. eng.

32. Hyman SE, Malenka RC, Nestler EJ. Neural mechanisms of addiction: the role of rewardrelated learning and memory. Annual review of neuroscience. 2006;29:565-98. PubMed PMID: 16776597. Epub 2006/06/17. eng.

33. Benyamin R, Trescot AM, Datta S, Buenaventura R, Adlaka R, Sehgal N, et al. Opioid complications and side effects. Pain physician. 2008 Mar;11(2 Suppl):S105-20. PubMed PMID: 18443635. Epub 2008/06/17. eng. 
34. Patten SB, Love EJ. Can drugs cause depression? A review of the evidence. J Psychiatry Neurosci. 1993 May;18(3):92-102. PubMed PMID: 8499431. Pubmed Central PMCID: PMC1188504. Epub 1993/05/01. eng.

35. Hölzel L, Härter M, Reese C, Kriston L. Risk factors for chronic depression - A systematic review. Journal of Affective Disorders. 2011 3//;129(1-3):1-13.

36. Campbell G, Mattick R, Bruno R, Larance B, Lintzeris N, Nielsen S, et al. The Pain and Opioids IN Treatment (POINT) study: Characteristics of a cohort using opioids to live with chronic non-cancer pain. Pain. in press.

37. Passik SD, Lowery A. Psychological Variables Potentially Implicated in Opioid-Related Mortality as Observed in Clinical Practice. Pain medicine (Malden, Mass). 2011;12(0 2):S36-S42. PubMed PMID: PMC4112122.

38. Stover BD, Turner JA, Franklin G, Gluck JV, Fulton-Kehoe D, Sheppard L, et al. Factors associated with early opioid prescription among workers with low back injuries. J Pain. 2006 Oct;7(10):718-25. PubMed PMID: 17018332. Epub 2006/10/05. eng.

39. Gourlay DL, Heit HA, Almahrezi A. Universal Precautions in Pain Medicine: A Rational Approach to the Treatment of Chronic Pain. Pain Medicine. 2005;6(2):107-12.

40. Passik SD, Kirsh KL. The interface between pain and drug abuse and the evolution of strategies to optimize pain management while minimizing drug abuse. Exp Clin Psychopharmacol. 2008 Oct;16(5):400-4. PubMed PMID: 18837636. Epub 2008/10/08. eng.

41. Williams AC, Eccleston C, Morley S. Psychological therapies for the management of chronic pain (excluding headache) in adults. Cochrane Database Syst Rev. 2012;11:CD007407. PubMed PMID: 23152245. Epub 2012/11/16. eng. 
Table 1. Demographic characteristics, mental health, pain and opioid medication history of POINT sample with and without depression broken down by onset of pain.

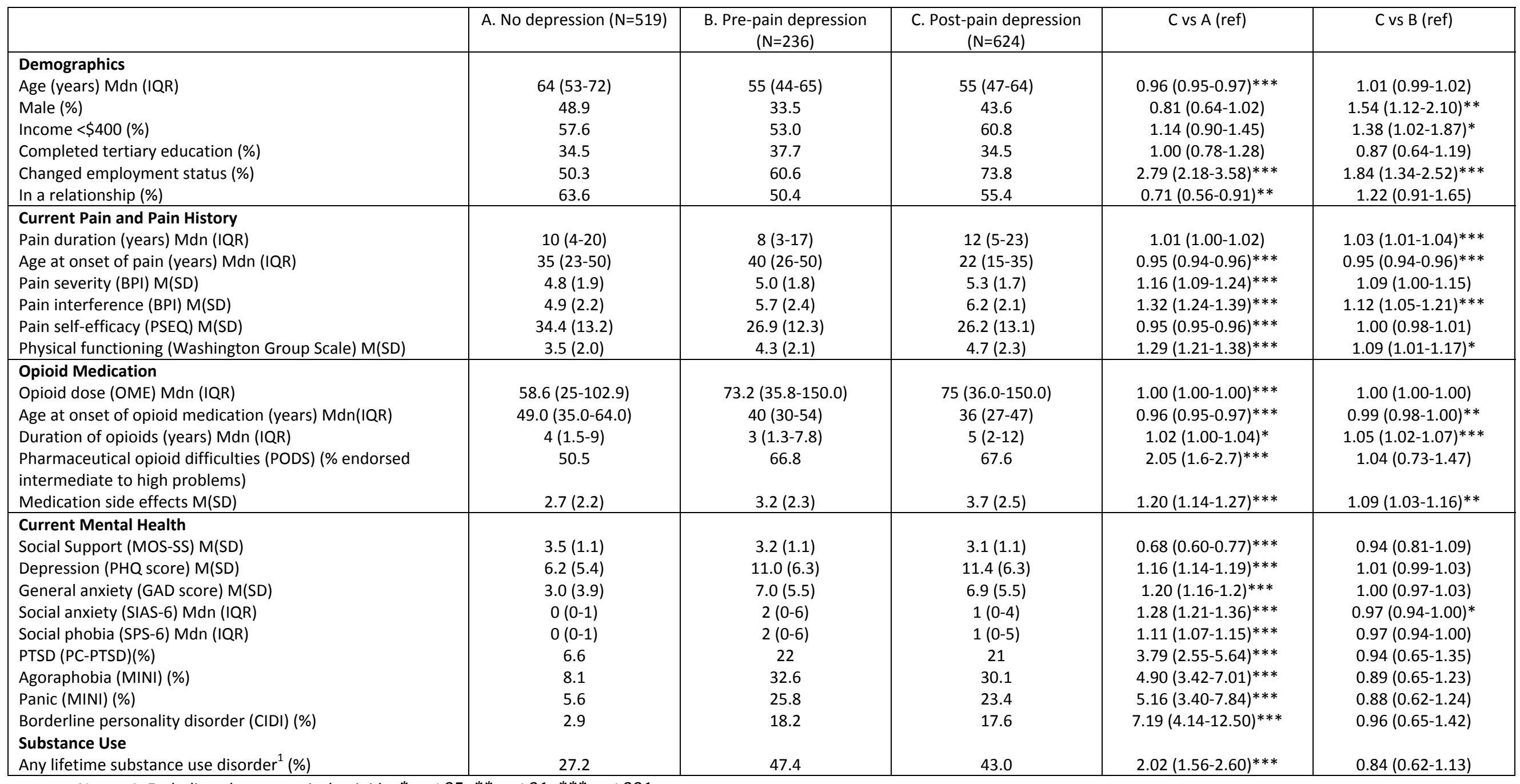

Notes: 1 . Excluding pharmaceutical opioids; ${ }^{*}=p \leq .05, * *=p \leq .01, * * *=p \leq .001$. 
Table 2. Multinomial regression comparing depression before and after pain with those with no history of depression ( $N=1379)$.

\begin{tabular}{|c|c|c|}
\hline & $\begin{array}{l}\text { Multivariate }^{\mathrm{a}} \\
\text { (RRR 95\%Cl) }\end{array}$ & $\begin{array}{c}\text { Multivariate }^{2 b} \\
\text { (RRR 95\%Cl) }\end{array}$ \\
\hline $\begin{array}{l}\text { Demographics } \\
\text { Age (years) } \\
\text { Male } \\
\text { Income }<\$ 400 \\
\text { Completed tertiary education } \\
\text { In a relationship } \\
\text { Change to employment status }\end{array}$ & $\begin{array}{c}0.96(0.93-0.98)^{* *} \\
0.39(0.25-0.62)^{* * *} \\
0.98(0.63-1.51) \\
0.76(0.49-1.18) \\
0.59(0.38-0.91)^{*} \\
0.90(0.57-1.43)\end{array}$ & $\begin{array}{c}1.00(0.99-1.03) \\
0.74(0.52-1.05) \\
1.21(0.87-1.69) \\
0.90(0.64-1.26) \\
0.89(0.63-1.26) \\
1.64(\mathbf{1 . 1 5 - 2 . 3 6 ) * *}\end{array}$ \\
\hline $\begin{array}{l}\text { Current Pain and Pain History } \\
\text { Pain severity } \\
\text { Pain interference } \\
\text { Pain self-efficacy } \\
\text { Physical functioning } \\
\text { Age at first pain onset (years) } \\
\text { Pain Duration (years) }\end{array}$ & $\begin{array}{c}0.93(0.81-1.07) \\
0.94(0.82-1.07) \\
0.97\left(0.95-0.99^{*}\right. \\
1.11(0.99-1.24) \\
1.05(1.03-1.07)^{* * *} \\
1.01(0.99-1.03)\end{array}$ & $\begin{array}{c}0.92(0.83-1.03) \\
1.05(0.94-1.17) \\
\mathbf{0 . 9 8}(\mathbf{0 . 9 7 - 1 . 0 0 ) *} \\
\mathbf{1 . 1 1}(\mathbf{1} .02-1.21)^{*} \\
\mathbf{0 . 9 7}(\mathbf{0 . 9 6 - 0 . 9 8 ) * * *} \\
1.00(0.99-1.01)\end{array}$ \\
\hline $\begin{array}{l}\text { Opioid Medication } \\
\text { Opioid dose (OME) } \\
\text { Age at onset of opioid medication } \\
\text { (years) } \\
\text { Duration of opioids (years) } \\
\text { Pharmaceutical opioid difficulties (\% } \\
\text { endorsed int/high problems) } \\
\text { Medication side effects }\end{array}$ & $\begin{array}{c}1.00(1.00-1.00) \\
0.98(0.96-1.00) \\
0.97(0.94-1.01) \\
1.63(1.01-2.63)^{*} \\
0.87(0.78-0.96)^{* *}\end{array}$ & $\begin{array}{l}1.00(1.00-1.00) \\
0.99(0.97-1.00) \\
1.00(0.98-1.02) \\
1.28(0.89-1.86) \\
1.00(0.93-1.08)\end{array}$ \\
\hline $\begin{array}{l}\text { Support } \\
\text { Social Support }\end{array}$ & $0.92(0.75-1.12)$ & $0.84(0.71-0.98)^{*}$ \\
\hline $\begin{array}{l}\text { Drug and Alcohol use } \\
\text { Any lifetime substance use disorder }\end{array}$ & $1.51(0.92-2.45)$ & $1.16(0.79-1.71)$ \\
\hline
\end{tabular}

Notes: Reference group is group $\mathrm{A} ;{ }^{*}=p \leq .05,{ }^{* *}=p \leq .01,{ }^{* * *}=p \leq .001$

$R^{2}=.197, p<.001$.

${ }^{a}$ comparison of pre-pain depression with those that had never experienced depression

${ }^{b}$ comparison of post-pain depression with those that had never experienced depression

1. Excluding pharmaceutical opioids

2.Controlling for PTSD, agoraphobia, panic and borderline personality. 
Table 3. Demographic characteristics, mental health, pain and opioid medication history of POINT sample with and without depression broken down by onset of opioids

\begin{tabular}{|c|c|c|c|c|c|}
\hline & A. No depression $(\mathrm{N}=519)$ & $\begin{array}{l}\text { B. Pre-opioid depression } \\
\qquad(\mathrm{N}=426)\end{array}$ & $\begin{array}{l}\text { C. Post-opioid depression } \\
\qquad(\mathrm{N}=416)\end{array}$ & C vs A (ref) & C vs B (ref) \\
\hline $\begin{array}{l}\text { Demographics } \\
\text { Age (years) Mdn (IQR) } \\
\text { Male }(\%) \\
\text { Income }<\$ 400(\%) \\
\text { Completed tertiary education (\%) } \\
\text { Changed employment status (\%) } \\
\text { In a relationship (\%) }\end{array}$ & $\begin{array}{c}64(53-72) \\
48.9 \\
57.6 \\
34.5 \\
50.3 \\
63.6 \\
\end{array}$ & $\begin{array}{c}57(46-66) \\
34.7 \\
60.1 \\
36.2 \\
65.2 \\
51.9 \\
\end{array}$ & $\begin{array}{c}54(46-62) \\
46.9 \\
57.0 \\
35.8 \\
74.0 \\
56.0 \\
\end{array}$ & $\begin{array}{c}0.95(0.94-0.96)^{* * *} \\
0.92(0.71-1.19) \\
0.97(0.75-1.26) \\
1.06(0.81-1.39) \\
2.82(2.13-3.73)^{* * *} \\
0.73(0.56-0.95)^{*} \\
\end{array}$ & $\begin{array}{c}0.99(0.98-1.00)^{*} \\
1.66(1.26-2.19)^{* * *} \\
0.88(0.67-1.16) \\
0.97(0.74-1.31) \\
1.52(1.13-2.05)^{* *} \\
1.18(0.90-1.55) \\
\end{array}$ \\
\hline $\begin{array}{l}\text { Current Pain } \\
\text { Pain duration (years) Mdn (IQR) } \\
\text { Age at onset of pain (years) Mdn (IQR) } \\
\text { Pain severity (BPI) M(SD) } \\
\text { Pain interference (BPI) M(SD) } \\
\text { Pain self-efficacy (PSEQ) M(SD) } \\
\text { Physical functioning (Washington Group Scale) M(SD) }\end{array}$ & $\begin{array}{c}10(4-20) \\
35(23-50) \\
4.8(1.9) \\
4.9(2.2) \\
34.4(13.2) \\
3.5(2.0) \\
\end{array}$ & $\begin{array}{c}10(4-20) \\
28(17-41) \\
5.1(1.8) \\
6.0(2.2) \\
26.7(12.3) \\
4.6(2.1) \\
\end{array}$ & $\begin{array}{c}13(6-21.75) \\
27(18-40) \\
5.3(1.6) \\
6.22(2.1) \\
26.3(13.5) \\
4.5(2.3) \\
\end{array}$ & $\begin{array}{c}1.01(1.00-1.02) \\
0.97(0.96-0.98)^{* * *} \\
1.17(1.08-1.25)^{* * *} \\
1.31(1.23-1.39)^{* * *} \\
0.95(0.94-0.96)^{* * *} \\
1.26(1.17-1.35)^{* * *}\end{array}$ & $\begin{array}{l}1.01(1.00-1.02) \\
1.00(0.99-1.01) \\
1.07(0.99-1.16) \\
1.06(0.99-1.13) \\
1.00(0.99-1.01) \\
0.99(0.93-1.00)\end{array}$ \\
\hline $\begin{array}{l}\text { Opioid Medication } \\
\text { Opioid dose (OME) Mdn (IQR) } \\
\text { Age at onset of opioid medication (years) Mdn(IQR) } \\
\text { Duration of opioids (years) Mdn (IQR) } \\
\text { Pharmaceutical opioid difficulties (PODS)(\% endorsed } \\
\text { int/high problems) } \\
\text { Medication side effects M(SD) }\end{array}$ & $\begin{array}{c}58.6(25-102.9) \\
49(35.0-64.0) \\
4(1.5-9) \\
50.5 \\
\\
2.7(2.2)\end{array}$ & $\begin{array}{c}67.00(30.3-149.1) \\
42(32.0-55.0) \\
4(1.5-10) \\
63.9 \\
3.3(2.4)\end{array}$ & $\begin{array}{c}86.2(40.0-177.5) \\
31.5(24.8-42.0) \\
6(2-12.75) \\
71.9 \\
3.8(2.6)\end{array}$ & $\begin{array}{c}1.00(1.00-1.01)^{* * *} \\
0.94(0.93-0.95)^{* * *} \\
1.03(1.01-1.04)^{* *} \\
2.51(1.85-3.41)^{* * *} \\
1.22(1.16-1.29)^{* * *}\end{array}$ & $\begin{array}{c}1.00(1.00-1.00)^{*} \\
0.95(0.95-0.96)^{* * *} \\
1.03(1.01-1.05)^{* * *} \\
1.44(1.04-1.99)^{*} \\
1.10(1.04-1.16)^{* * *}\end{array}$ \\
\hline $\begin{array}{l}\text { Current Mental Health } \\
\text { Social Support (MOS-SS) M(SD) } \\
\text { Depression (PHQ score) M(SD) } \\
\text { General anxiety (GAD score) M(SD) } \\
\text { Social anxiety (SIAS-6) Mdn (IQR) } \\
\text { Social phobia (SPS-6) Mdn (IQR) } \\
\text { PTSD (PC-PTSD) (\%) } \\
\text { Agoraphobia (MINI) (\%) } \\
\text { Panic (MINI) (\%) } \\
\text { Borderline personality disorder (CIDI) (\%) } \\
\text { Substance Use } \\
\text { Any lifetime substance use disorder }{ }^{1}(\%)\end{array}$ & $\begin{array}{c}3.5(1.1) \\
6.2(5.4) \\
3.0(3.9) \\
0(0-1) \\
0(0-1) \\
6.6 \\
8.1 \\
5.6 \\
2.9\end{array}$ & $\begin{array}{c}3.1(1.1) \\
11.1(6.3) \\
7.1(5.5) \\
2(0-5) \\
2(0-6) \\
23.9 \\
32.6 \\
24.6 \\
19.0\end{array}$ & $\begin{array}{c}3.1(1.1) \\
11.6(6.3) \\
6.8(5.5) \\
1(0-4) \\
1(0-5) \\
18.8 \\
27.9 \\
24.5 \\
16.1\end{array}$ & $\begin{array}{c}0.67(0.59-0.77)^{* * *} \\
1.17(1.14-1.20)^{* * *} \\
1.20(1.16-1.23)^{* * *} \\
1.27(1.20-1.34)^{* * *} \\
1.10(1.06-1.15)^{* * *} \\
3.29(2.15-5.04)^{* * *} \\
4.39(3.0-6.43)^{* * *} \\
5.49(3.55-8.49)^{* * *} \\
6.45(3.63-11.48)^{* * *}\end{array}$ & $\begin{array}{c}0.97(0.85-1.12) \\
1.01(0.99-1.03) \\
0.99(0.97-1.02) \\
0.96(0.93-0.99)^{*} \\
0.97(0.94-1.00)^{*} \\
0.73(0.53-1.02) \\
0.80(0.59-1.07) \\
0.99(0.73-1.36) \\
0.82(0.57-1.17)\end{array}$ \\
\hline
\end{tabular}

Notes: 1. Excluding pharmaceutical opioids; ${ }^{*}=p \leq .05,{ }^{* *}=p \leq .01,{ }^{* * *}=p \leq .001$. 
Table 4. Multinomial regression comparing depression before and after opioids with those with no history of depression $(\mathrm{N}=1361)$

\begin{tabular}{|c|c|c|}
\hline & Multivariate $^{\mathrm{a}}$ & $\begin{array}{l}\text { Multivariate }^{2 b} \\
\text { (OR 95\%Cl) }\end{array}$ \\
\hline $\begin{array}{l}\text { Demographics } \\
\text { Age (years) } \\
\text { Male } \\
\text { Income }<\$ 400 \\
\text { Completed tertiary education } \\
\text { In a relationship } \\
\text { Change in employment status }\end{array}$ & $\begin{array}{c}0.97(0.95-0.99)^{* *} \\
0.46(0.31-0.67)^{* * *} \\
1.18(0.83-1.69) \\
0.95(0.67-1.36) \\
0.64(0.45-0.92)^{*} \\
1.17(0.79-1.72) \\
\end{array}$ & $\begin{array}{l}1.01(0.99-1.03) \\
0.84(0.57-1.24) \\
1.06(0.73-1.55) \\
0.84(0.58-1.22) \\
0.89(0.61-1.31) \\
1.37(0.91-2.05) \\
\end{array}$ \\
\hline $\begin{array}{l}\text { Current Pain } \\
\text { Pain severity } \\
\text { Pain interference } \\
\text { Pain self-efficacy } \\
\text { Physical functioning } \\
\text { Age at first pain onset (years) } \\
\text { Pain Duration (years) }\end{array}$ & $\begin{array}{c}0.92(0.82-1.04) \\
1.00(0.89-1.12) \\
0.98(0.96-1.00)^{*} \\
1.14(1.04-1.25)^{* *} \\
0.98(0.97-0.99)^{* *} \\
1.00(0.99-1.02)\end{array}$ & $\begin{array}{c}0.94(0.83-1.06) \\
1.04-1.17) \\
0.98(0.97-1.00) \\
1.11(1.01-1.22)^{*} \\
1.01(0.99-1.02) \\
1.00(0.98-1.02)\end{array}$ \\
\hline $\begin{array}{l}\text { Opioid Medication } \\
\text { Opioid dose (OME) } \\
\text { Age at onset of opioid medication (years) } \\
\text { Duration of opioids (years) } \\
\text { Pharmaceutical opioid difficulties (\% } \\
\text { endorsed int/high problems) } \\
\text { Medication side effects }\end{array}$ & $\begin{array}{c}1.00(1.00-1.00) \\
1.03(1.01-1.05)^{* *} \\
1.00(0.97-1.02) \\
1.38(0.93-2.05) \\
0.92(0.85-1.01)\end{array}$ & $\begin{array}{c}1.00(1.00-1.00) \\
0.94(0.93-0.96)^{* * *} \\
1.00(0.98-1.03) \\
1.58(1.04-2.39)^{*} \\
1.00(0.92-1.09)\end{array}$ \\
\hline $\begin{array}{l}\text { Support } \\
\text { Social Support }\end{array}$ & $0.86(0.73-1.02)$ & $0.79(0.66-0.95)^{*}$ \\
\hline $\begin{array}{l}\text { Drug and Alcohol use } \\
\text { Any lifetime substance use disorder }\end{array}$ & $1.43(0.94-2.17)$ & $1.04(0.69-1.59)$ \\
\hline
\end{tabular}

Notes: Reference group is group A, ${ }^{*}=p \leq .05,{ }^{* *}=p \leq .01,{ }^{* * *}=p \leq .001$

$R^{2}=.17, p<.001$.

${ }^{a}$ comparison of pre-opioid depression with those that had never experienced depression

${ }^{b}$ comparison of post-opioid depression with those that had never experienced depression

1. Excluding pharmaceutical opioids

2.Controlling for PTSD, agoraphobia, panic and borderline personality. 